\title{
The Effect of Family-Friendly System in SMEs on Positive Ps ychological Capital and Job Stress of Employees
}

\author{
Kil-Won Im, Department of Smart Production and Management Engineering, Hanbat National \\ University,125 Dongseodaero, Yuseong-gu, Daejeon 34158, Korea \\ Jae-Yong Lee, Department of Smart Production and Management Engineering, Hanbat National \\ University,125 Dongseodaero, Yuseong-gu, Daejeon 34158, Korea \\ Soo-Yong Park, Department of Smart Production and Management Engineering, Hanbat National \\ University,125 Dongseodaero, Yuseong-gu, Daejeon 34158, Korea \\ *Dong-Hyung Lee, Department of Smart Production and Management Engineering, Hanbat National \\ University,125 Dongseodaero, Yuseong-gu, Daejeon 34158, Korea, leedh@hanbat.ac.kr \\ ${ }^{*}$ Corresponding author
}

\begin{abstract}
In recent years, as women's social activities has increased and the roles of female workers has been important, the need for a family-friendly system is emerging. At this point, it is necessary to examine whether the family-friendly system is actually fulfilling its purpose in SMEs. In this study, we try to find out the actual situation of SMEs that have been certified as family-friendly, and to analyze the effect of family-friendliness on the positive psychological capital and job stress of employees. We conducted a questionnaire survey to analyze the effects of the family-friendly system on the positive psychological capital and job stress of employees in family-friendly certified SMEs. 150 valid questionnaires collected were conducted basic statistical analysis, reliability analysis and regression analysis using SPSS Statistics and Smart PLS. The results of analysis are as follows. First, only flexible working system among six sectors of SMEs' family affinity system has a positive (+) positive effect on positive psychological capital. Second, among family affinity system of SMEs, only family relationship promotion and leisure support have a negative effect on job stress. In other words, it was found that job stress at work decreased as family relationship promotion and leisure life support were activated. Third, positive psychological capital has a negative effect on job stress. Therefore, as the positive psychological capital of employees increases, job stress of employees decreases. Fourth, flexible working system has lowered job stress through positive psychological capital. This result means that flexible work system has a negative effect on job stress, and more strongly influence job stress reduction through positive psychological capital. Improvements/Applications: In order to improve the efficiency of the family-friendly system of SMEs in the future, revitalization of the flexible working system, development of positive psychological capital improvement programs, enhancement of support for family relations and leisure life, and evaluation index improvement are required.
\end{abstract}

Keywords: SMEs, Family-friendly System, Positive psychological capital, Job Stress, flexible work system.

$\begin{array}{lll}\text { Received: 07.12.2020 } & \text { Accepted: 10.01.2021 } & \text { Published: 05.02.2021 }\end{array}$

\section{INTRODUCTION}

Family-friendly system has introduced under the Act on the Promotion of the Creation of a FamilyFriendly Social Environment in 2008. The purpose of this system is to harmonize family life and work life in harmony with changes in the social environment such as low birth rate and aging population etc. That is, it pursuits to improve the competitiveness of the company by improving the quality of life of workers' families and by increasing economic activity of women, workers and employees. The family-friendly system, which has been implemented for more than 10 years, is a system that grants family-friendly system through screening for companies that have been implementing family-friendly standards. The system began with 11 companies certified in 2008, and as of 2018, a total of 3,300 companies and organizations have been certified. These figures indicate that the company's participation in the familyfriendly system has steadily increased [1]. However, despite this quantitative expansion, this system should be improved in many aspects [2]. Therefore, the purpose of this study is to find out The Effect of SME Family-Friendly System on Positive Psychological Capital and Job Stress of members and to propose improving measures. 


\section{LITERATURE REVIEW}

\section{Family friendliness}

Family-friendliness refers to the creation of an environment where work and life balance are possible [3], and has six types [1] as follows. 1) Workers' health management and life cycle support. 2) Childbirth and parenting support. 3) Flexible work support. 4) Family care and health support. 5) Promoting family relationships and supporting leisure life. 6) It is a family-friendly social contribution.

'Family-friendly certification' is a system that grants certification through screening for companies and governmental public institutions that best operate the family-friendly system. The targets for applying for family-friendly certification are central administrative agencies and local governments, public corporations, private companies, and universities etc. The certification evaluation items consist of leadership and family-friendly systems, family-friendly management performance, and employee satisfaction. The Ministry of Gender Equality and Family selects and accredits family-friendly system companies and organizations through written review and on-site review and deliberation by the certification committee through the annual application for family-friendly system.

The validity of family-friendly system is 3 years from the date of certification and can be extended within 2 years. With the introduction of family-friendly management, the quality of life between workers and family members is improved, and the competitiveness of companies, such as the reduction of turnover, is strengthened. It also has a positive effect on enhancing the corporate image by using the certification mark on products and corporate promotion. Companies that have been certified can receive additional points when participating in government projects of five ministries, such as the Small and Medium Business Administration and the Public Procurement Service.

\section{Positive psychological capital}

Positive Psychological Capital is the process of having confidence in one's abilities in accomplishing a task, optimistic about current and future success, persevering toward a goal, and revising or re-assigning a goal to a problem situation or difficulty. It can be defined as a complex and positive cognitive state [4]. Positive psychological capital can be defined as the upper concept that integrates four sub-components of selfefficacy, hope, optimism, and resilience as psychological competency factors included in the category of positive organizational behavior [5].

The four sub-components of positive psychological capital are as follows.

1) Self-efficacy: Self-efficacy is any confidence or belief in one's ability to successfully perform a particular task in a given environment.

2) Hope: Hope is a positive motivation for the willingness to pursue and the path to achieving the goal, believing that the set goal can be achieved and the plan will be successful.

3) Optimism: Optimism means that something bad in your life rarely and temporarily appears, and that more good will happen. In general, optimism is defined as positive expectations for the future and pessimism as negative expectations.

4) Resiliency: Resilience is said to be an individual's internal, psychological, and social ability to use the strengths inherent in an individual to face it in a normal or positive direction..

\section{Job stress}

Job stress is defined as a detrimental physical and emotional reaction that occurs when job requirements do not match workers' abilities, resources, desires or demands [6]. In general, the factors causing job stress are divided into eight: physical environment, job demand, lack of job autonomy, relationship conflict, job instability, organizational system, inadequate compensation, and workplace culture [7]. A brief explanation of these eight factors is as follows.

First, the physical environment is a physical environmental factor in which workers are exposed, and refers to air pollution, risks of work methods, and physical burden. Second, job demand refers to the degree of job burden, and includes time pressure, job interruption, increase in workload, sense of responsibility, excessive job, and multi-functionality. Third, the lack of job autonomy implies job decisionmaking authority and level of discretion, and includes technical discretion and autonomy, possibility of job prediction, and job performance authority. Fourth, relational conflict is caused by lack of communication between the boss and colleagues within the company. Fifth, job instability refers to the safety of one's job or job, and includes job search opportunities and overall job instability. Sixth, the organizational system refers to the organization's strategy and operating system, organizational resources, conflict within the organization, rational communication, and promotion potential. Seventh, inadequate 
compensation means the appropriateness of the degree of compensation expected for work, and includes financial compensation, respect, internal motivation, expected compensation, and opportunities for technological development. Eighth, workplace culture refers to Korean collectivism, job conflict, lack of a rational communication system, and sexual discrimination.

\section{Review of existing research}

Kang and Choi [8] said that the more workers working in a company with a strong family-friendly organizational culture, the lower the workplace-home conflict. Jeong [3] stated that work-family harmony is a strategy that satisfies the needs of workers and companies at the same time, and it is very important to create a family-friendly corporate culture. Therefore, it is necessary to review whether requests from the field are communicated to the management smoothly, how the management responds to them, and whether a family-friendly organizational culture is formed. Park [9] verified that organizational commitment and organizational member behavior were significant parameters in the relationship between positive psychological capital and job satisfaction. Kim [10] demonstrated that positive emotions have significant indirect mediating effects on job satisfaction and emotional commitment, and negative emotions have significant indirect mediating effects only on emotional commitment. Kim et al [11] showed that self-leadership plays a complete mediating role in the relationship between positive psychological capital and organizational member behavior in a study on airline workers. Park [12] stated that organizational commitment plays a partial mediating role in the relationship between positive psychological capital and organizational member behavior. Park [7] stated that job stress affects worker satisfaction, behavioral results such as turnover, performance, absenteeism, and cognitive and physical results, but the degree varies depending on the level of stress or individual differences. Lee [13] stated that positive psychological capital had a negative effect on job stress excluding self-efficacy among subfactors, and a negative effect on job stress variables excluding job demand.

\section{RESEARCH DESIGN}

\section{Research model}

In this study, a research model was set up as shown in Figure 1 to understand the effect of family-friendly system on positive psychological capital and job stress. Here, the family-friendly system consists of 37 measuring indicators. It means 6 'self-health management and life cycle support' (F-A) programs, 11 'childbirth and parenting support' (F-B) programs, 5 'flexible working' (F-C) programs, 4 'family nursing and family health support' (F-D) programs, 6 'family relations promoting and leisure life supporting' (F-E) programs, and 5 'family-friendly social contribution' (F-F) programs.

On the other hand, measuring indicators of positive psychological capital consists of four including self-efficacy, resilience, optimism, and hope. And job stress consists of eight such as physical environment, job demand, job autonomy, relationship conflict, job insecurity, organizational system, inadequate compensation, and workplace culture. 


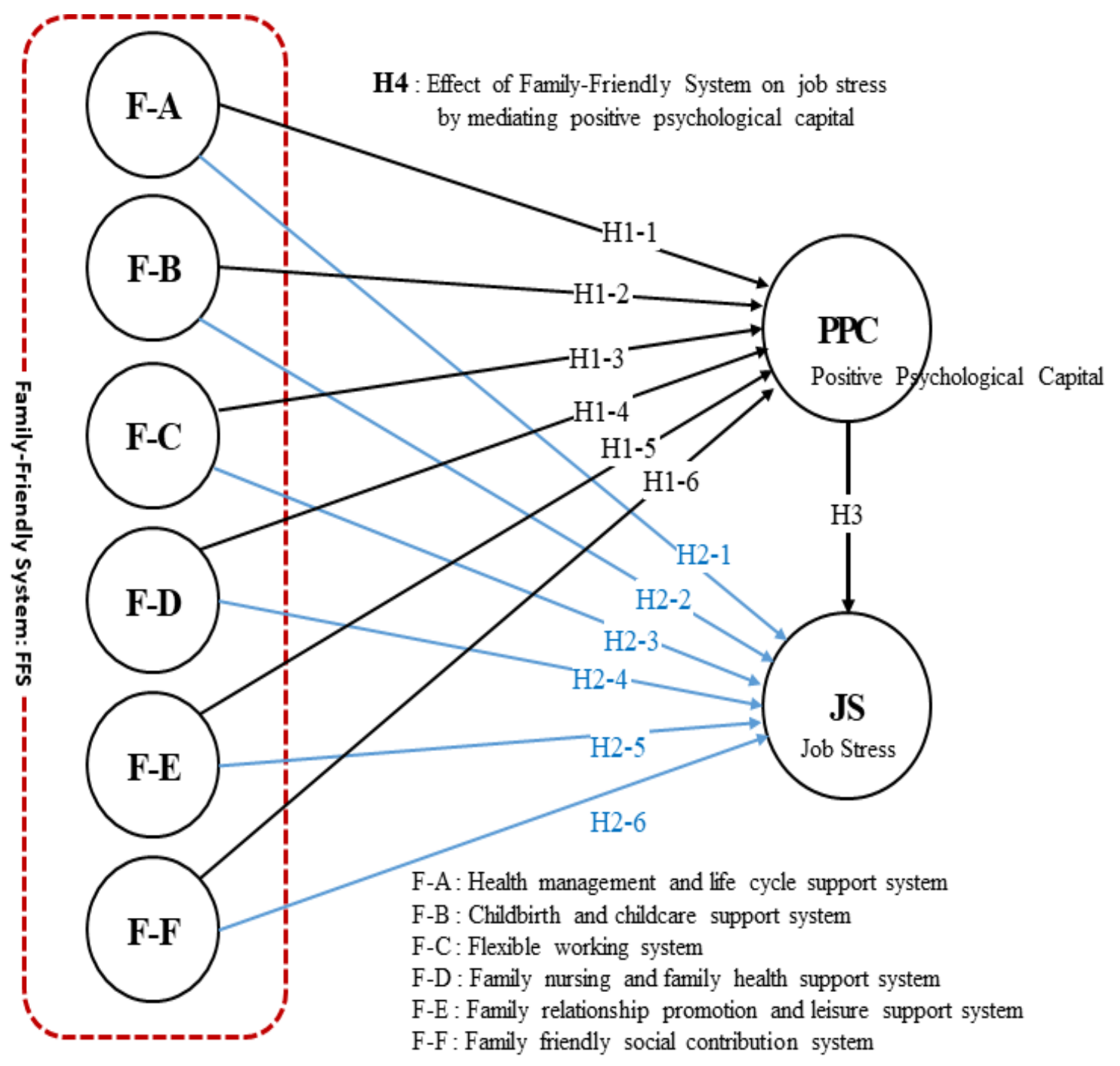

Figure 1 Research Model

\section{Research hypothesis}

19 hypotheses that family-friendliness will affect positive psychological capital and job stress are set as shown in Table 1.

Table 1. Hypothesis Related to Positive Psychological Capital and Job Stress

\begin{tabular}{|l|l|}
\hline Hypothesis1-1 & F-A will have a positive impact on Positive psychological capital \\
\hline Hypothesis1-2 & F-B will have a positive impact on Positive psychological capital \\
\hline Hypothesis1-3 & F-C will have a positive impact on Positive psychological capital \\
\hline Hypothesis1-4 & F-D will have a positive impact on Positive psychological capital \\
\hline Hypothesis1-5 & F-E will have a positive impact on Positive psychological capital \\
\hline Hypothesis1-6 & F-F will have a positive impact on Positive psychological capital \\
\hline Hypothesis2-1 & F-A will have a negative impact on job stress \\
\hline Hypothesis2-2 & F-B will have a negative impact on job stress \\
\hline Hypothesis2-3 & F-C will have a negative impact on job stress \\
\hline Hypothesis2-4 & F-D will have a negative impact on job stress \\
\hline Hypothesis2-5 & F-E will have a negative impact on job stress \\
\hline
\end{tabular}




\begin{tabular}{|l|l|}
\hline Hypothesis2-6 & F-F will have a negative impact on job stress \\
\hline Hypothesis3-1 & $\begin{array}{l}\text { Positive psychological capital will have a negative impact on job } \\
\text { stress }\end{array}$ \\
\hline Hypothesis4-1 & $\begin{array}{l}\text { F-A will have a negative impact on job stress through positive } \\
\text { psychological capital. }\end{array}$ \\
\hline Hypothesis4-2 & $\begin{array}{l}\text { F-B will have a negative impact on job stress through positive } \\
\text { psychological capital. }\end{array}$ \\
\hline Hypothesis4-3 & $\begin{array}{l}\text { F-C will have a negative impact on job stress through positive } \\
\text { psychological capital. }\end{array}$ \\
\hline Hypothesis4-4 & $\begin{array}{l}\text { F-D will have a negative impact on job stress through positive } \\
\text { psychological capital. }\end{array}$ \\
\hline Hypothesis4-5 & $\begin{array}{l}\text { F-E will have a negative impact on job stress through positive } \\
\text { psychological capital. }\end{array}$ \\
\hline Hypothesis4-6 & $\begin{array}{l}\text { F-F will have a negative impact on job stress through positive } \\
\text { psychological capital. }\end{array}$ \\
\hline
\end{tabular}

\subsection{Operational definition of variables and questionnaire composition}

The scale of positive psychological capital is measured by revising the 24 items used in Choi et al [14]'s research based on four factors such as self-efficacy, resilience, hope, and optimism suggested by Luthans et al [15].

The job stress scale is measured by the Korea Safety and Health Agency's basic job stress measurement tool, which has been modified to suit family-friendly SMEs. The questionnaire was organized as shown in Table 2.

Table 2. Composition of Questionnaire Items

\begin{tabular}{|c|c|c|c|c|}
\hline \multirow{2}{*}{\multicolumn{2}{|c|}{ Variables }} & \multicolumn{2}{|c|}{ Survey question } & \multirow{2}{*}{ Sources } \\
\hline & & \multirow{2}{*}{$\begin{array}{l}\text { No } \\
\text { I.2.1 6 }\end{array}$} & \multirow{2}{*}{$\begin{array}{l}\text { Each } \\
6\end{array}$} & \\
\hline \multirow{6}{*}{$\begin{array}{l}\text { Family-Friendly } \\
\text { System }\end{array}$} & F-A & & & \multirow{6}{*}{$\begin{array}{l}\text { Ministry of Gende } \\
\text { Equality anc } \\
\text { Family }\end{array}$} \\
\hline & F-B & I.3.1 11 & 11 & \\
\hline & $\mathrm{F}-\mathrm{C}$ & I.4.1 5 & 5 & \\
\hline & F-D & I.5 1 1 4 & 4 & \\
\hline & F-E & I.6.1 6 & 6 & \\
\hline & F-F & I.7.1 5 & 5 & \\
\hline \multirow{4}{*}{$\begin{array}{l}\text { Positive } \\
\text { psychological } \\
\text { capital }\end{array}$} & Self-efficacy & II.1 6 & 6 & Luthans[13] \\
\hline & Hope & II.7 12 & 6 & \\
\hline & Resilience & II.13 18 & 6 & \\
\hline & Optimism & II.19 24 & 6 & \\
\hline \multirow{8}{*}{ Job stress } & Job demands & III.1 3 & 3 & \multirow{7}{*}{$\begin{array}{l}\text { Korean Job Stress } \\
\text { Measurement } \\
\text { Tool(Korea } \\
\text { Occupational Safety } \\
\text { \& Health Agency) }\end{array}$} \\
\hline & Insufficient job control & III.4 11 & 8 & \\
\hline & Occupational climate & III.12 16 & 5 & \\
\hline & Lack of reward & III.17 20 & 4 & \\
\hline & Organizational system & III.21 26 & 6 & \\
\hline & Interpersonal conflict & III.27 33 & 7 & \\
\hline & Job instability & III.34 39 & 6 & \\
\hline & Optimism & III.40 43 & 4 & \\
\hline $\begin{array}{l}\text { General } \\
\text { characteristics }\end{array}$ & & IV. $1 \sim 5$ & 5 & \\
\hline
\end{tabular}

\section{Data collection and analysis method}


In this study, the results and limitations of previous studies were reviewed, and appropriate research hypotheses were established and a questionnaire survey was conducted as follows. First, the survey period was conducted for 30 days. Second, the survey area was set to Daejeon, Sejong, and Chungcheong. Third, the subjects of the survey were selected from SME workers who received family-friendly system. Fourth, the number of survey subjects was about 200 people. The survey was conducted and the number of questionnaires collected were 160. Among them, 10 questionnaires of companies with poorly operated family-friendly system were excluded, and a total of 150 questionnaires were statistically analyzed through IBM SPSS Statistics 22.0 and Smart PLS 3.0.

\section{RESULTS}

\section{Respondent characteristics and family-friendly system management status}

\section{Respondent general characteristics}

As for the gender of respondents, males (67.2\%) were more than females (32.7\%), and looking at the age ratio, 30 s were the highest with $39.4 \%$ (15.3\% in $20 \mathrm{~s}, 30.7 \%$ in $40 \mathrm{~s}, 12.7 \%$ in $50 \mathrm{~s}, 2.0 \%$ in $60 \mathrm{~s}$ ). The position was general employee was $35.3 \%$, assistant manager $23.3 \%$, senior manager $27.4 \%$, department head $6.0 \%$, and executive director $8.0 \%$. It means that the deputy level accounted for a greater proportion than the executives. The number of years of service for respondents was 3 to less than 5 years $(26.7 \%), 5$ to less than 10 years (23.3\%), 1 to 3 years (19.3\%), less than 1 year (18.0\%), and less than 10 to 20 years (11.3), 20 years or more (1.3\%). It means that respondents less than 5 years (64\%) accounted for a greater proportion than 5 years or more (36\%).

\section{Operating status of family-friendly system}

Table 3 shows the operating status of family-friendly system (FFS) companies participating in this study.

Table 3. Operation status of FFS

\begin{tabular}{|l|l|l|}
\hline Family-Friendly System & Mean utilization (5.0) & Converted score (100 point) \\
\hline F-A & 3.67 & 73.4 \\
\hline F-B & 3.53 & 70.6 \\
\hline F-C & 3.23 & 64.6 \\
\hline F-D & 3.20 & 64.0 \\
\hline F-E & 3.30 & 66.0 \\
\hline F-F & 3.31 & 66.2 \\
\hline F-A & 3.67 & 73.4 \\
\hline F-B & 3.53 & 70.6 \\
\hline
\end{tabular}

When evaluating as 5.0(100 points), the system utilization on average of companies with familyfriendly system as follows: Their health management and life cycle support was 3.67(73.4 points), and childbirth and parenting support system 3.53(70.6 points), flexible working system 3.23(64.6 points), family nursing and family health support system 3.20(64.0 points), family relations promotion and familyfriendly social contribution system 3.30 (66.0 points), family-friendly social contribution system 3.31 (66.2 points).

In addition, the detailed operating programs that are frequently used by certified companies for family-friendliness include health care support, leave and leave system exceeding legal standards, prohibition of working on night holidays for pregnant workers, regular leave of absence system and vacation payment support.

\section{Analysis for the measurement model}

In the PLS-SEM analysis process, securing the reliability and validity of the scale (measured variable and latent variable) is a very important issue. Therefore, when estimating a structural model, the reliability and validity of the measurement model scale must be secured in advance [16]. First, looking at the Composite Reliability and Cronbach's alpha coefficient for the research model, as shown in $<$ Table $4>$, the reliability of the composition concept of the variables is more than 0.7 and the Cronbach's alpha coefficient is more than 0.6 , so it can be evaluated that the reliability is secured.

Table 4. Composite Reliability and Cronbach's alpha 


\begin{tabular}{|l|l|l|l|}
\hline \multicolumn{2}{|l|}{ Variables } & Composite Reliability & Cronbach's alpha \\
\hline \multirow{4}{*}{$\begin{array}{l}\text { Family-Friendly } \\
\text { System }\end{array}$} & F-A & 0.928 & 0.908 \\
\cline { 2 - 4 } & F-B & 0.931 & 0.920 \\
\cline { 2 - 4 } & F-C & 0.933 & 0.910 \\
\cline { 2 - 4 } & F-D & 0.875 & 0.814 \\
\cline { 2 - 4 } & F-E & 0.935 & 0.917 \\
\cline { 2 - 4 } & F-F & 0.982 & 0.977 \\
\hline \multicolumn{2}{|l|}{ Positive psychological capital } & 0.971 & 0.960 \\
\hline Job stress & 0.749 & 0.697 \\
\hline
\end{tabular}

Even if constituent concept reliability or Cronbach's alpha is confirmed, AVE (average variance extracted), which represents the centralized validity of the measurement items used for empirical analysis, should be at least 0.5 . As shown in Table 5, because the AVE value of job stress is 0.356 , we removed job demand (-0.15), workplace culture (0.157), physical environment (0.297), and job insecurity (0.498) which an outer loadings value is less than 4 , and measured AVE value again. As a result, AVE value was in 0.646, and the baseline was met. Therefore, empirical analysis was conducted on the final 45 measurement items.

Table 5. AVE (average variance extracted) value

\begin{tabular}{|l|l|l|}
\hline \multicolumn{2}{|l|}{ Variables } & AVE \\
\hline \multirow{4}{*}{ Family-Friendly System } & F-A & 0.682 \\
\cline { 2 - 3 } & F-B & 0.554 \\
\cline { 2 - 3 } & F-C & 0.735 \\
\cline { 2 - 3 } & F-D & 0.638 \\
\cline { 2 - 3 } & F-E & 0.706 \\
\cline { 2 - 3 } & F-F & 0.916 \\
\hline \multicolumn{2}{|l}{ Positive psychological capital } & 0.971 \\
\hline Job stress & 0.749 \\
\hline
\end{tabular}

\section{Structural model evaluation and hypothesis verification}

\section{Structural model evaluation}

Once the reliability and validity of the measurement model is confirmed, the next step is to evaluate the structural model. In PLS-SEM, multi-collinearity (VIF), coefficient of determination $\left(R^{2}\right)$, effect size $\left(f^{2}\right)$, and predictive suitability $\left(Q^{2}\right)$ should be evaluated to evaluate the structural model. First, the multicollinearity problem can be determined to be solved because the variance inflation factor (VIF), which is a multi-collinearity statistic, is less than 5 as shown in Table 6.

Table 6. Evaluation results of VIF

\begin{tabular}{|l|l|l|l|}
\hline \multicolumn{2}{|l|}{ Variables } & Composite Reliability & Cronbach's alpha \\
\hline \multirow{4}{*}{$\begin{array}{l}\text { Family-Friendly } \\
\text { System }\end{array}$} & ( ) F-A & 3.249 & 3.271 \\
\cline { 2 - 4 } & (2) F-B & 2.724 & 2.791 \\
\cline { 2 - 4 } & (3) F-C & 2.983 & 3.236 \\
\cline { 2 - 4 } & (4) F-D & 3.487 & 3.490 \\
\cline { 2 - 4 } & (5) F-E & 3.902 & 3.919 \\
\cline { 2 - 4 } & (6) F-F & 2.820 & 2.854 \\
\hline 7) Positive psychological capital & & 1.348 \\
\hline 8) Job stress & & \\
\hline
\end{tabular}


Second, the evaluation results for the exogenous potential variable, family friendliness, the endogenous potential variable, positive psychological capital, and the determinant coefficient (R2), which are explanatory power for job stress, are shown in Table 7. The explanatory power of exogenous potential variables on endogenous potential variables is above the intermediate level.

Table 7. Evaluation results of $R^{2}$

\begin{tabular}{|l|l|l|}
\hline Variables & $\boldsymbol{R}^{\mathbf{2}}$ & Adjusted $\boldsymbol{R}^{\mathbf{2}}$ \\
\hline Positive psychological capital & 0.258 & 0.227 \\
\hline Job stress & 0.623 & 0.604 \\
\hline Variables & $R^{2}$ & Adjusted $R^{2}$ \\
\hline
\end{tabular}

Third, looking at the evaluation results of the effect size, which is a criterion for evaluating the relative effect of exogenous potential variables to endogenous potential variables, it shows a small or medium effect as shown in Table 8.

Table 8. Evaluation results of $f^{2}$

\begin{tabular}{|l|l|l|l|}
\hline \multicolumn{2}{|l|}{ Variables } & Composite Reliability & Cronbach's alpha \\
\hline \multirow{4}{*}{$\begin{array}{l}\text { Family-Friendly } \\
\text { System }\end{array}$} & (1) F-A & 0.007 & 0.004 \\
\cline { 2 - 4 } & (2) F-B & 0.024 & 0.005 \\
\cline { 2 - 4 } & (3) F-C & 0.085 & 0.006 \\
\cline { 2 - 4 } & (4) F-D & 0.001 & 0.007 \\
\cline { 2 - 4 } & (5) F-E & 0.004 & 0.046 \\
\hline & (6) F-F & 0.012 & 0.003 \\
\hline \multicolumn{2}{|l}{ (7) Positive psychological capital } & & 0.692 \\
\hline (8) Job stress & & \\
\hline
\end{tabular}

Meanwhile, by performing blindfolding in the SmartPLS program, the predictive suitability $(=1$ SSE/SSO) of exogenous potential variables for specific endogenous potential variables in the structural model was calculated as shown in Table 9. As a result of the analysis, the values for the endogenous potential variables, positive psychological capital and job stress, were 0.210 and 0.363 , respectively, values greater than zero and can be judged as having suitability.

Table 9. Evaluation results of $Q^{2}$

\begin{tabular}{|l|l|l|l|l|}
\hline \multicolumn{2}{|l|}{ Variables } & Composite Reliability & Cronbach's alpha & \\
\hline \multirow{4}{*}{$\begin{array}{l}\text { Family-Friendly } \\
\text { System }\end{array}$} & F-A & 900.000 & 900.000 & \\
\cline { 2 - 5 } & F-B & $1,650.000$ & $1,650.000$ & \\
\cline { 2 - 5 } & F-C & 750.000 & 750.000 & \\
\cline { 2 - 5 } & F-D & 600.000 & 600.000 & \\
\cline { 2 - 5 } & F-E & 900.000 & 900.000 & 0.210 \\
\cline { 2 - 5 } & F-F & 750.000 & 750.000 & 0.363 \\
\hline Positive psychological capital & 600.000 & 474.137 & \\
\hline Job stress & 600.000 & 382.364 & \\
\hline
\end{tabular}

\section{Hypothesis verification}

For hypothesis verification for 19 hypotheses, the bootstrapping procedure was performed using the SmartPLS program, and the results are as shown in Table 10. Summarizing this is as follows.

First, the path coefficient for the effect of the flexible working system on positive psychological capital was 0.433 , the $t$ value was 3.308 , and the $p$ value was 0.001 . Therefore, the system that affects the positive psychological capital is the flexible working system, and it can be said that the more the flexible working system is activated, the positive psychological capital of the members increases. 
Second, the path coefficient for the effect of the promotion of family relations and the leisure life support system on job stress was -0.260 , the $t$ value was 2.634 , and the $p$ value was 0.009 . Therefore, it can be said that the job stress of members decreases as the family relations promotion and leisure life support system become active.

Third, the path coefficient for the effect of positive psychological capital on job stress was -0.593 , t value was 9.558, and p value was 0.000 . This suggests that job stress is lowered when employees' positive psychological capital is high, as is the result of previous studies.

Fourth, the path coefficient for the effect of the flexible work system on job stress through positive psychological capital was -0257 , and its $t$ value was 3.162 and p value was 0.002 . This suggests that the flexible working system has a stronger indirect effect on job stress through positive psychological capital.

Table10. Hypothesis Related to Positive Psychological Capital and Job Stress

\begin{tabular}{|l|l|l|}
\hline \multicolumn{2}{|l}{ Hypothesis } & Result \\
\hline $1-1$ & F-A will have a positive impact on Positive psychological capital & $\times$ \\
\hline $1-2$ & F-B will have a positive impact on Positive psychological capital & $\times$ \\
\hline $1-3$ & F-C will have a positive impact on Positive psychological capital & $\circ(+)$ \\
\hline $1-4$ & F-D will have a positive impact on Positive psychological capital & $\times$ \\
\hline $1-5$ & F-E will have a positive impact on Positive psychological capital & $\times$ \\
\hline $1-6$ & F-F will have a positive impact on Positive psychological capital & $\times$ \\
\hline $2-1$ & F-A will have a negative impact on job stress & $\times$ \\
\hline $2-2$ & F-B will have a negative impact on job stress & $\times$ \\
\hline $2-3$ & F-C will have a negative impact on job stress & $\times$ \\
\hline $2-4$ & F-D will have a negative impact on job stress & $\circ(-)$ \\
\hline $2-5$ & F-E will have a negative impact on job stress & $\times$ \\
\hline $2-6$ & F-F will have a negative impact on job stress & $\times$ \\
\hline $3-1$ & Positive psychological capital will have a negative impact on job stress & $\circ(-)$ \\
\hline $4-1$ & F-A will have a negative impact on job stress through positive psychological capital. & $\times$ \\
\hline $4-2$ & F-B will have a negative impact on job stress through positive psychological capital. & $\times$ \\
\hline $4-3$ & F-C will have a negative impact on job stress through positive psychological capital. & $\circ(-)$ \\
\hline $4-4$ & F-D will have a negative impact on job stress through positive psychological capital. & $\times$ \\
\hline $4-5$ & F-E will have a negative impact on job stress through positive psychological capital. & $\times$ \\
\hline $4-6$ & F-F will have a negative impact on job stress through positive psychological capital. & $\times$ \\
\hline & & \\
\hline
\end{tabular}

\section{CONCLUSIONS}

In this study, the status of application of the system was investigated for companies and institutions that have been certified by the family-friendly system. And the effect of the SME's family-friendly system on the positive psychological capital and job stress of its members was analyzed. The analysis results of this study are as follows.

First, it can be seen that the more the flexible working system is activated in SMEs, the higher the positive psychological capital of the members. Second, it can be seen that job stress at work decreases as family relations and leisure support are activated. Third, the higher the positive psychological capital of SME members, the lower the job stress. Fourth, it was found that the flexible working system lowered job stress through positive psychological capital. This suggests that the flexible working system has a negative $(-)$ effect on job stress, but it has a stronger effect on job stress reduction through positive psychological capital. In summary, it is judged that the current family-friendly system is very difficult to apply to SMEs. Therefore, the following improvement measures are required to make it a family-friendly system suitable for SMEs.

First, the flexible working system should be further activated to improve the positive psychological capital of its members. Second, it is necessary to reduce job stress by promoting family relations and revitalizing leisure life support, and expanding time spent with family members. Third, it is necessary to develop various programs that can increase the positive and psychological capital of members. Fourth, it is necessary to apply the differential weight of the family-friendly system and improve 
the evaluation index. In accordance with the reality of SMEs, it is necessary to differentiate the weight of each family-friendly level and improve it into an evaluation index that allows workers to be satisfied and actively participate. Fifth, the government should strengthen support to activate the family-friendly system. In addition, it is necessary to provide active financial support for corporate tax reductions for SMEs that voluntarily operate the system, recruitment of assistants for family-friendly management, and facility investment. Sixth, SMEs need continuous improvement and complementary efforts for various problems that appeared in the operation process through systematic performance management and monitoring for the family-friendly system.

Since this study was aimed at members of family-friendly SMEs in Daejeon, Sejong, and Chungcheong (Korea), it has limitations in expanding and applying the research results to all SME members in Korea. In future studies, it is necessary to verify the results of this study by expanding the sample volume targeting SME members nationwide. In addition, this study focused on the effectiveness and verification of the system utilization of the family-friendly system, but in future studies, it is necessary to further verify the personal necessity and the aspects of satisfaction of the family-friendly system. In addition, it is considered necessary to study specific measures to increase positive psychological capital.

\section{REFERENCES}

Mogef.go.kr [Internet]. Korea: Ministry of Gender Equality and Family. [updated 2019 Apr 12; cited 2020 Jul 9]. Available from: http://www.mogef.go.kr.

Kang MJ, Moon JS, Lim HJ. A Study on the Performance Analysis and Improvement Suggestions of Familyfriendly Certification System. Korean Woman's Development Institute. 2018.

Jeong YK. The necessity and recommendation on the family-friendly policy for integrating work and family. The Journal of Korean Family Resource Management Association. 2002; 6(2): 143-155.

Jung JY. A Study on the Impact of Positive Psychological Capital on Creativity: Mediating Effect of Job Stress in the Center [dissertation]. [Seoul (Korea)]: Chung-Ang University; 2016.

Luthans F \& Youssef CM. Human, Social and Now Positive Psychological Capital Management: Investing in People for Competitive Advantage, Organizational Dynamics. 2004; 33(2):143-160.

Park JO. The Empirical Study on the Preventive Management Strategy of the Job Stress [dissertation]. [Daejeon (Korea)]: HanNam University; 2008.

Park YS, Park SY, Lee DH. The Effects of Job Stress of Construction Workers on Construction Accidents and Turnover Intention. Journal of Society of Korea Industrial and Systems Engineering. 2017; 40(3): 59-65.

Kang HR, Choi SY. Antecedents and Outcomes of Work-Family Conflict of Married Working Women. The Journal of The Korean Society for Woman Psychology. 2001; 6(1): 23-42.

Park SG, Seong OH, Lee HR. The Effect of Hotel Employees' Psychological Capital on Job SatisfactionFocused on the Mediating Effect of Organizational Commitment and Organizational Citizenship Behavior. Korea Journal of Business Administration. 2010; 23(5): 2565-2584.

Kim GY, Kim KS, Lee DM. The Relationship among Self Leadership, Organizational Citizenship Behavior, and Psychological Capital of Airline Personnel. Journal of Aviation Management Society of Korea. 2012; 10(1): 111-129.

Kim GH. Antecedents of positive psychological capital [dissertation]. [Jeju (Korea)]: Jeju University; 2013.

Park JC. Mediating Effects of Organizational Commitment on the Relationship between Positive Psychological Capital and Organizational Citizenship Behavior of University Staff in Korea. Journal of The Korean-Japanese Economic \& Management Association. 2012; 57: 227-249.

Lee HJ, Park SY, Lee DH. The Effects of Positive Psychological Capital on Job Stress of Construction Workers. Journal of Society of Korea Industrial and Systems Engineering. 2017; 40(4): 230-236.

Choe YD, Jeong HJ, Lee DS. Leader`s Use of Humor and Employees` Performance and Work Happiness: The Moderating Role of Trust in Leader and the Mediating Role of Positive Psychological Capital. Korea Business Review. 2012; 41(3): 575-605.

Luthans F, Avolio BJ, Avey JB \& Norman SM. Positive psychological capital: measurement and relationship with performance and satisfaction. Personnel Psychology. 2007; 60(3): 541-572.

Kim TM. The Effects of Transformational Leadership on Team Performances: Focused on Semi-conductor Manufacturing [dissertation]. [Seoul (Korea)]: Hoseo University; 2017. 